This is a peer-reviewed, accepted author manuscript of the following research article: Shaw, D., \& Morton, A. (Accepted/In press). Counting the cost of denying assisted dying. Clinical Ethics.

\title{
Counting the Cost of Denying Assisted Dying
}

\section{Abstract}

In this paper we propose and defend three economic arguments for permitting assisted dying. These arguments are not intended to in provide a rationale for legalising assisted suicide or euthanasia in and of themselves; rather, they are supplementary arguments that should not be neglected when considering the ethics of assisted dying. The first argument is that permitting assisted dying enables consenting patients to avoid negative quality-adjusted life years (QALYs), enabling avoidance of suffering. The second argument is that the resources consumed by patients who are denied assisted dying could instead be used to provide additional QALYs for patients elsewhere in the healthcare system who wish to continue living and to improve their quality of life. The third argument is that organ donation may be an additional potential source of QALYs in this context. We also anticipate and provide counterarguments to several objections to our thesis. Taken together, the cumulative avoidance of negative QALYs and gain in positive QALYs suggest that permitting assisted dying would substantially benefit both the small population that seeks assisted suicide or euthanasia, and the larger general population. As such, denying assisted dying is a lose-lose situation for all patients.

\section{Introduction}

Quality-adjusted life years (QALYs) have been used for decades in healthcare allocation decision-making. By combining quality of life and mortality into one metric, 
they enable quantification of the medical gains and losses and relative financial costs of a vast diversity of treatments and interventions, in turn enabling these different treatments to be compared against each other and funding decisions to be made..$^{1,2,3}$ QALYs are also used by organisations such as the National Institute for Health and Care Excellence and the Scottish Medicines Consortium to decide whether treatments are too expensive to made available on the National Health Service $(\mathrm{NHS})^{4,5}$. For example, NICE often uses the rough rule that new treatments should not exceed a cost of $£ 30,000$ per QALY. ${ }^{6}$

QALYs (and their close relation, disability-adjusted life years) have faced some criticism on ethical grounds. In particular it is charged that they discriminate against older patients who will gain fewer QALYs per intervention (because of their age)7; or differently abled patients (because the definition of "full health" used presupposes e.g. mobility). ${ }^{8}$ Nonetheless, the use of QALYs provides an important discipline to thought. Even in countries (such as the Netherlands or Norway) which have adopted additional formal criteria incorporating equity concerns, calculations of QALY gain play an important role in supporting decision making ${ }^{9-10}$ There is a substantial ethical literature discussing both the ethical (or unethical) nature of QALYS themselves, and critiquing different decisions reached using QALY. Where QALYS have generally been neglected, however, is in the debate regarding assisted dying. As we show in the paper, the QALY has the potential to unlock important new additional arguments in favour of the case for assisted dying. In this paper we use "assisted dying" to indicate both assisted suicide and euthanasia, though the former is perhaps more likely to be legalised, at least in the United Kingdom. 


\section{The primary economic argument for assisted dying: avoiding negative QALYs}

Proponents of assisted dying and euthanasia often argue that death is the only way for some patients to avoid immense suffering. Some make this argument using the phrase "worse than death" or "a life not worth living" which has proven controversial. For example, Bobbie Farsides has argued that the latter phrase is not a useful one. ${ }^{11}$ There are indeed philosophical difficulties in comparing known suffering with the unknowns of death, but Farsides herself concedes that patients who are competent and wish to die but are denied the chance to do so because of the illegality of assisted dying should be compensated:

Competent adults may claim that their life is not worth living and that they wish their life to end. Such claims must be investigated sympathetically. If the claims persist despite optimum care and in the absence of depression healthcare professionals must find ways to compensate such patients for the fact that society has denied them the means to exercise their autonomy. How patients could or should be compensated has not been determined.

In health economics QALYs are used to evaluate health gains. A QALY is a consequentialist measure of health which involves multiplying the time in a health state by a factor which represents the quality of life experienced in that health state. Most health states are preferable to death, and so attract a quality of life score which is greater than zero, indicating that life in that health state is preferable to no life at all. (Roudijk et al discuss the reasons why it is appropriate to set death as the zero of the quality of life scale). ${ }^{12}$ However, some limited literature has examined the value of health states worse than death. For example, Patrick and colleagues 
conducted a study among well adults and nursing home residents and found that "Most respondents evaluated their current health and severe constant pain as better than death; dementia and coma were more often considered equal to or worse than death”, and so dementia and coma would attract a negative QALY weight. In this study, both the states rated as worse than death were hypotheticals not yet experienced by patients, ${ }^{13}$ but the evidence suggests that most of those who seek assisted dying do so in order to avoid unattractive outcomes, so at least regard death as preferable to continuing life. ${ }^{14}$

If the goal is to maximise positive QALYs and minimise negative QALYs (time in states scored worse than death), assisted dying can be seen as a relatively low-cost intervention. For example, if one person continue to live for two years with a Quality of Life score of -.5 , provision of assisted suicide would result in a net gain of 1 QALY at well below the NICE threshold mentioned above. In the remainder of the text we discuss some ways in which the overall QALYs from assisted dying might be calculated: the logic of our calculations is summarized in Table 1.

What would the cumulative QALY benefits be in terms of negative QALYs avoided if assisted dying were permitted in the UK? The numbers of deaths in the UK in 2017 was $607,172\left(533,253\right.$ in England and Wales, ${ }^{15}, 57,883$ in Scotland, ${ }^{16}$ and 16,036 in Northern Ireland ${ }^{17}$ ). What percentage of these deaths would be assisted if assisted dying were legalised? For a high estimate, we may consider the case of the Netherlands, where $4 \%$ of deaths are now assisted, ${ }^{18}$ which would translate to 24,287 deaths in the UK. For a low estimate, we may consider Oregon, where approximately $0.4 \%$ of deaths are assisted ( $133^{19}$ out of a total of 36,640 deaths in 
$2017^{20}$ ), which would translate to 2,429 deaths in the UK context. (Note that the legal situation differs between the Netherlands and Oregon: the Netherlands permits euthanasia, which accounts for a large share of the deaths, whereas Oregon allows assisted suicide whereby terminally ill patients who wish to die can access lifeending medication). 


\begin{tabular}{|c|c|c|c|c|}
\hline & Quantity & Notation & High scenario & $\begin{array}{l}\text { Low } \\
\text { scenario }\end{array}$ \\
\hline & Total annual deaths & $\Omega$ & 607,172 & 607,172 \\
\hline & $\begin{array}{l}\% \text { of deaths which could be } \\
\text { assisted }\end{array}$ & $r$ & 0.04 & 0.004 \\
\hline Baseline figures & Potential assisted deaths & $a=\Omega \times r$ & 24,287 & 2,429 \\
\hline \multirow{3}{*}{$\begin{array}{r}\text { Calculation of } \\
\text { QALYs from time } \\
\text { in state worse } \\
\text { than death } \\
\text { averted }\end{array}$} & $\begin{array}{l}\text { Averted time in bad health } \\
\text { state per assisted death } \\
\text { (years) }\end{array}$ & $\mathrm{t}$ & 0.33333333 & 0.333333 \\
\hline & $\begin{array}{l}\text { Quality of life score of bad } \\
\text { health state }\end{array}$ & $\mathrm{h}$ & -0.25 & -0.25 \\
\hline & $\begin{array}{l}\text { QALYS for averted life in } \\
\text { states worse than death }\end{array}$ & Q1=-axt $\times h$ & 2,024 & 202 \\
\hline \multirow{4}{*}{$\begin{array}{r}\text { Calculation of } \\
\text { QALYs from } \\
\text { resource savings }\end{array}$} & $\begin{array}{l}\text { Resource saving per } \\
\text { assisted death }\end{array}$ & $\mathrm{m}$ & 3,064 & 3,064 \\
\hline & Total resource savings & $\mathrm{s}=\mathrm{a} \times \mathrm{m}$ & $74,406,905$ & $7,440,690$ \\
\hline & Cost per QALY valuation & $\lambda$ & 30,000 & 30,000 \\
\hline & $\begin{array}{l}\text { QALYS from investing } \\
\text { resource savings }\end{array}$ & $Q 2=s / \lambda$ & 2,480 & 248 \\
\hline \multirow{3}{*}{$\begin{array}{r}\text { Calculations of } \\
\text { QALYs from organ } \\
\text { donation }\end{array}$} & $\begin{array}{l}\text { \% of assisted deaths where } \\
\text { assistance results in organ } \\
\text { donation }\end{array}$ & $\mathrm{p}$ & 0.05 & 0.05 \\
\hline & $\begin{array}{l}\text { QALYs gained from each } \\
\text { death with organ donation }\end{array}$ & d & 12 & 12 \\
\hline & $\begin{array}{l}\text { QALYS from additional } \\
\text { organ donations }\end{array}$ & $Q 3=a \times p \times d$ & 14,572 & 1,457 \\
\hline
\end{tabular}

Table 1. Calculations of the QALY gains from legalizing assisted dying 
The total number of QALYs which would be realized (or negative QALYs which are averted) by legalizing assisted dying depends on the "weight" of each death in QALY terms. Suppose that each assisted death saves 4 months of suffering (the Oregon law, for example, requires that patients seeking assisted dying must have at most 6 months to live), and that such a life would have a Quality of Life score of -0.25 . In that case, 2,024 negative QALYs would be averted on our high Netherlands uptake scenario and 202 negative QALYs in our low Oregon uptake scenario. Once again, we stress that avoiding suffering and respecting autonomy remain the primary arguments for assisted dying; this and the following economic arguments are additional and supplementary.

The secondary economic argument for assisted dying: gaining positive QALYs

The QALY benefits of permitting assisted dying are already substantial even if we only consider the patients who are helped to die. But further QALY gains are possible because denying access to assisted dying means that patients remain alive (against their wishes), and this can often necessitate considerable consumption of resources. For example, a patient who is in great pain because of cancer with a life expectancy of around two years will continue to require pain medication and support from clinical staff and also carers for those two years. For each such patient, legalising assisted dying would avoid this waste of resources. 
Competent patients who wish to access assisted dying, but need these resources because their wish is not granted represents a violation of the autonomy of these patients. If they happened to actively require life-support, they could ask for it to be turned off, but for most patients this is not an option. ${ }^{21}$ This particular violation of autonomy is two-fold; these patients do not wish to continue living, but because they must do so, they require resources that they would prefer were used to save and improve other patients' lives.

What quantity of resources might be saved from legalizing assisted dying? It is possible to get a rough sense of the magnitude. Many patients who seek assisted dying are suffering from cancer (e.g. around $2 / 3$ in the Netherlands) and Round et al estimate that 12 months of care for a cancer patient at the end of life costs $£ 9,914$, including, health, social, charity and informal care. ${ }^{22}$ If only one third of these costs could be saved through assisted dying, at the UK level this would translate to $£ 74 \mathrm{~m}$ in the high scenario and $£ 7.4 \mathrm{~m}$ in the low scenario. This money could be used to purchase 2,480 or 248 QALYs respectively at the $£ 30,000$ per QALY rate, or indeed could be spent addressing other moral challenges faced by the health system, such as reducing inequalities in health linked to deprivation. This is an additional economic argument for legalising assisted dying; in no way is it intended to suggest that any such care should be denied to any patient.

The tertiary economic argument for assisted dying: QALY gain through organ donation 
In addition to the two preceding economic arguments in favour of assisted dying, there is also a tertiary argument. Allowing patients to access assisted dying enables many of them to become organ donors. Despite the assumption that donation is not possible after assisted suicide or euthanasia, in many countries this is a reality for patients. Only cancer is normally a contraindication. Patients who are denied assisted dying could also end up donating their organs, but there are several reasons why donation after assisted dying is better from a clinical and economic perspective. First, if patients are denied assisted dying, organ function will gradually deteriorate until they die naturally, meaning that transplantation is less likely to be successful. Second, patients who choose assisted dying have to go through a lengthy process, and organ donation can be easily integrated into that process (noncoercively), decreasing the risk that family members will attempt to overrule donation, which often occurs when a patient dies in a way that is not planned. Finally, because of the planned nature of the death, it is even possible that a tissue match could be found before the organs are explanted..$^{23}$ For all these reasons, enabling assisted dying could also enable an additional, highly beneficial source of organs for transplantation. The primary argument is that enabling assisted dying avoids suffering; the second is that doing so frees up more resources for other patients. This third argument is similar to the second, but actually involves patients choosing to share their organs - a precious resource- with others after they die.

As noted above, many of those who seek assisted dying are suffering from cancer and for such patients their organs would not be available for transplantation. However, it is clear that the QALY benefits of having access to organs for translation can be significant (see Table 1 in Nunnink and Cook $^{24}$ for a summary of the 
evidence). Evidence from Belgium suggests that $10 \%$ of those accessing euthanasia could donate at least one organ. ${ }^{25}$ Even if only $5 \%$ of those seeking assisted dying are enabled thereby to donate their organs, but this leads to 12 additional QALYS being gained from the transplantation (bearing in mind that more than one organ may be made available), then the benefits may be substantial: 14,572 QALYs in the high scenario and 1,457 QALYs in the low scenario. Once again, this is a supplemental argument to the foregoing economic arguments, and organ donation is an extra benefit that can flow from euthanasia, not a direct reason for legalising assisted dying.

\section{Objections}

We anticipate two main objections to the three arguments we have presented here. The first is that it is callous to consider assisted dying from the perspective of resource management; these are real people with real lives. This criticism is misplaced. Part of the motivation for our argument is precisely that these are real people with real lives who wish to avoid suffering. As we have striven to make clear, we are simply arguing that the economic costs of denying assisted dying should not be ignored; they should not be the key driver of any legal change, but it would be irresponsible not to consider them. Our argument simply shows that permitting assisted dying would help such people avoid negative QALYs, while also yielding QALY benefits for other patients. Indeed, as denying an assisted death causes actual harm to others, it may force a patient into a situation where their core ethical beliefs are violated. Consider the case of a dying consequentialist. Her healthcare costs in her last agonising few months push the overall cost-benefit calculation for 
her life into the red: alongside the physical and psychological trauma of dying, she now must bear the moral horror of having consumed more than she has produced, and made a negative net contribution to the world. Hence, we see assisted dying as enabling patients to live lives which are more fully consistent with their own ethical values (consequentialist or not).

A counter-counter-objection might be that, even if economic considerations are only secondary and not primary, even mentioning them might make people feel pressured to seek assisted dying rather than to continue as a patient who (like any other) imposes costs on the healthcare system. This is a variant of the 'burden' argument against assisted dying, which holds that if it is legalised, people who do not really want to die but feel they are burdening their relatives will seek assisted suicide or euthanasia. It is true that knowledge of the costs averted by legalising assisted dying could provide another avenue for burden-type thinking. However, our primary argument is about averting suffering for individual patients (albeit at a larger population scale), and as such is not vastly dissimilar to typical autonomy and harmavoidance arguments in favour of assisted dying. Furthermore, it is not clear why information about the actual costs of maintaining the prohibition of assisted dying should be withheld from citizens. If society is to make informed decisions about assisted dying, all relevant evidence should be considered.

The second objection is that our argument relies on negative QALYs, and that use of this concept in this context is fundamentally flawed. Barrie has made this argument at some length, specifically with the aim of defeating resource arguments against permitting assisted dying, so we consider his objections in detail here. One 
of his concerns is that death is not specific enough; he argues that "'Death' might include the process of dying, whereas 'being dead' would not." ${ }^{26}$ This is simply wrong; death is the state after the dying process is complete.

Barrie's main argument is that "preferences about euthanasia involve more than comparisons between states (e.g. death), and indeed more than comparisons between events (e.g. dying), because they also involve actions (e.g. killing), that is, changes in states that are brought about in a particular way." This may be true, but it is no argument against the use of QALYs in this particular context. The fact that killing (or self-killing) is part of assisted dying does not change the fact that assisted dying can remove negative QALYs. Arguing about semantics does not change that.

Barrie also argues that proponents of assisted dying draw a false equivalence: "The intuitively plausible idea that there are some states of living which are so unbearable that one might be better off dead is taken to be equivalent to the idea that commissioned killing would be preferable to these states". But no-one argues this. Rather, we argue that this idea is justification for allowing assisted dying, subject to the sort of control which have been introduced in countries where assisted dying has been legalised.

Adopting the patient's perspective, Barrie also argues that "The QALY cannot make sense of a patient who might believe that their suffering would be relieved when they are dead, and welcome the prospect of death for that reason, while at the same time not wanting to undergo the process of dying and thus preferring to postpone their death." But the QALY doesn't need to "make sense of" this, though it easily can. 
Here we simply have a patient who is in state A and would prefer to be in State D but doesn't want to undergo B (painful death) or C (assisted dying). Most patients who wish to access assisted dying do not want to delay dying; they want to accelerate it (though some may want to know whether it is an option without wanting to access it yet; this can provide valuable reassurance even for those who never end up dying with assistance). In a similar vein, he argues that "Death is problematical for the QALY because death needs to be imaginable as 'death-for-me' if we are to have preferences about its realization, and this ties one down to a very specific notion of death: as an imagined health state, or as some property that one can have and then lose." But death doesn't need to be an imagined health state. It may just be an absence of suffering or any experience at all, which for many people is preferable to ongoing suffering/negative QALYs.

\section{Conclusion}

We have suggested and defended three economic arguments that support permitting assisted dying for competent patients who wish to end their lives. While the modelling assumptions might be contested and the empirical basis of our calculations could be stronger if better data was available, our main point is that it is possible to get a sense of the order of magnitude of the population-level health benefits that could flow from legalizing assisted dying. The legal arrangements for assisted dying vary widely from country to country, and if the UK was to legalise assisted dying (presumably in the form of assisted suicide) the calculations here could be made more precise based on the specifics of the approach under consideration. Nevertheless, our paper shows in general that denying dying 
plausibly imposes great costs on both patients who wish to die and those who do not. A slightly counterintuitive finding of our analysis is that (given the admittedly rough and ready numbers we use) the benefits to the individual patients who chose assisted dying may in fact be outweighed by the broader benefits to society through reduced resource use and the improved potential for organ donation. However, our argument is not that legalisation of assisted dying should be primarily based on economic arguments; these are supplemental facts that should not be neglected. Legalising assisted dying in the UK is likely to yield a substantial increase in QALYs across the patient population as a whole.

\section{References}

1. Williams A. The value of QALYS. In Stephen Holland (ed.), Arguing About Bioethics. Routledge 2012:423

2. Drummond MF, Sculpher MJ, Claxton K, et al. Methods for the Economic Evaluation of Health Care Programmes. Oxford: OUP 2015.

3. Neumann PJ, Sanders GD, Russell LB, et al. Cost-Effectiveness in Health and Medicine. 2nd edition. Oxford: OUP 2017.

4. Ogden J. QALYs and their role in the NICE decision-making process. Prescriber 2017;28:41-43.

5. Scottish Medicines Consortium. How we make our decisions. https://www.scottishmedicines.org.uk/how-we-decide/ (Accessed 11/3/19)

6. National Institute for Health and Care Excellence (NICE). Carrying NICE over the threshold. https://www.nice.org.uk/news/blog/carrying-nice-over-the-threshold

(Accessed 11/3/19)

7. Harris J. QALYfying the value of life. Journal of Medical Ethics 1987,13,117-123

8. John TM, Millum J, Wasserman D. How to Allocate Scarce Health Resources without Discriminating against People with Disabilities. Econ Philos 2017;33(2):16186.

9. Ottersen T, Forde R, Kakad M, et al. A new proposal for priority setting in Norway: Open and fair. Health Policy 2016;120(3):246-51.

10. Reckers-Droog VT, van Exel NJA, Brouwer WBF. Looking back and moving forward: On the application of proportional shortfall in healthcare priority setting in the Netherlands. Health Policy 2018;122(6):621-29.

11. Farsides B, Dunlop RJ. Is there such a thing as a life not worth living? BMJ 2001 Jun 16; 322(7300): 1481-1483.

12. Roudijk B, Donders ART, Stalmeier PFM. Setting Dead at Zero: Applying Scale Properties to the QALY Model. Med Decis Making 2018;38(6):627-34.

13. Patrick et al. Measuring Preferences for Health States Worse than Death. Med Decis Making 1994;14:9-18. 
14. Pearlman RA, Hsu C, Starks $\mathrm{H}$, et al. Motivations for physician-assisted suicide. J Gen Intern Med 2005;20(3):234-9.

15. Office for National Statistics. Deaths registered in England and Wales: 2017. https://www.ons.gov.uk/peoplepopulationandcommunity/birthsdeathsandmarriages/d eaths (Accessed 11/3/19)

16. National Records of Scotland. Vital Events Reference Tables 2017

Section 5: Deaths https://www.nrscotland.gov.uk/statistics-and-

data/statistics/statistics-by-theme/vital-events/general-publications/vital-eventsreference-tables/2017/section-5-deaths (Accessed 11/3/19)

17. Northern Ireland Statistics and Research Agency. Death statistics 2017. https://www.nisra.gov.uk/publications/death-statistics (Accessed 11/3/19)

18. European Institute of Bioethics. Report 2016 euthanasia in Netherlands https://www.ieb-eib.org/en/document/report-2016-euthanasia-in-netherlands488.html (Accessed 11/3/19)

19. Oregon Health Authority. Oregon Death with Dignity Act: Data summary 2016. https://www.oregon.gov/oha/ph/providerpartnerresources/evaluationresearch/deathw ithdignityact/documents/year19.pdf (Accessed 11/3/19)

20. Oregon Health Authority. Annual Report Volume 2: Deaths and Perinatal Deaths Data

https://www.oregon.gov/oha/PH/BIRTHDEATHCERTIFICATES/VITALSTATISTICS/ ANNUALREPORTS/VOLUME2/Pages/index.aspx (Accessed 11/3/19)

21. Shaw D. The body as unwarranted life-support. J Med Ethics 2007;33(9):519-21. 22. Round J, Jones L, Morris S. Palliat Med. Estimating the cost of caring for people with cancer at the end of life: A modelling study. Palliat Med 2015 Dec;29(10):899907.

23. Shaw D. Organ Donation After Assisted Suicide: A Potential Solution to the Organ Scarcity Problem. Transplantation 2014 98: 247-251.

24. Nunnink L, Cook DA. Palliative ICU beds for potential organ donors: an effective use of resources based on quality-adjusted life-years gained. Crit Care Resusc. 2016 Mar;18(1):37-42.

25. Bollen J, van Smaalen $T$, ten Hoopen $R$, et al. Potential Number of Organ Donors After Euthanasia in Belgium. JAMA. 2017;317(14):1476-1477. doi:10.1001/jama.2017.0729

26. Barrie S. QALYs, euthanasia and the puzzle of death. J Med Ethics 201;41(8):635-8. 